\title{
AN INTERNAL COMBUSTION WATER PUMP
}

\author{
THE INGENIOUS INVENTION OF H. A. HUMPHREY
}

Widespread interest has been aroused in European Wineering circles in a new type of pump that has been evolved by a well-known English engineer, $\mathrm{Mr}$. H. A. Humphrey, M. Inst, C. E. It is based upon an entirely new principle, and is a revolutionary departure from existing practice, the novelty of the design compelling as much attention as its remarkable afficiency and economy.

The pump is based on the funda mental principle of internal explosion but does away with all the usual working parts of a gas engine, such as the piston, connecting. rod, crankshaft, fly wheel, two-to-one gear cams and bearings. There are no moving parts what ever except the sim ple mushroom valves, which ope and close automat

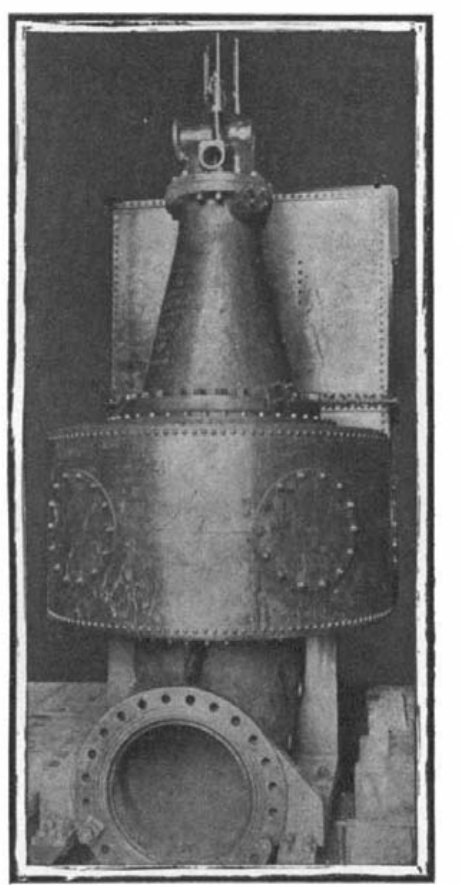

INTERNAL COMBUSTION WATEB POMP. cally, due to pressure changes, and the use of a flywheel is not necessary because a column of water, forming part of the water pumped, acts as a recipro- cating flywheel. The water column, which also acts as a piston, has four unequal strokes, such as theor requires when expansion is carried to atmospheric pressure. These strokes comprise long strokes durin combustion and expansion as well as during exhaust, a shorter stroke during suction, and a still shorter stroke during compression. There is no valve across the discharge pipe at any point, so that the water has a perfectly free passage from the explosion chamber to the high-level tank.

The explosive mixture of gas and air is ignited, as in the ordinary internal-combustion engine, and in contact with one end of a column of water, which fulflls the dual function of piston and flywheel, and moves so as to draw in a fresh combustible charge, to compress this charge previous to explosion, to permit expansion to be carried to atmospheric pressure, and finally to exhaust the products of combustion. All these movements are brought about and controlled by changes in the momentum, which occur naturally in the column of water itself.

In order to explain the cycle of operations in a pump o the simplest type, a reference to the accom panying diagram will be found useful. The pump proper is built up from three main castings. There is the combustion chamber $C$, the water valve chambe $W$, and the bend $B$, which connects the pump to the discharge pipe $D$, leading to the elevated tank $E T$. The suction tank $S T$ is extended to embrace the valve-box chamber, as shown, so that there is free access of water to all the water valves $\nabla$. The last are plain mushroom valves, opening inward, and held on their seating by light springs. In the top of th combustion chamber is an inlet valve $A$, as well as an exhaust valve $E$. Arranged between these two valves is a simple interlocking device, so that when valve
$A$ has opened and closed it locks itself shut, and releases valve $E$, and when valve $E$ has opened and closed it locks itself shut and releases valve $A$. Consequently, each time suction occurs in the chamber, these valves open in turn.

For the purpose of demonstration, suppose a gaseous charge is compressed in the top of the combustion chamber $C$, and is ignited in the usual manner by the sparking plug, which projects through the top casting or head of the combustion chamber. All the valves are shut at the instant the charge is exploded, and

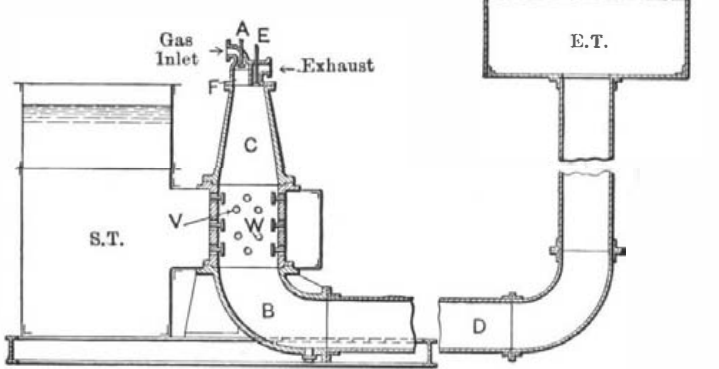

SECTIONAL VIEW OF INTERNAL COMBUSTION PUMP.

the increase in pressure resulting from the expanded gases forces the water downward in the pump, and sets the whole column of water in the bend $B$ and discharge pipe $D$ in motion. The column of water attains kinetic energy while work is being done upon it by the expanding gases, so that when those gases finally expand to atmospheric pressure, the column of water may be moving, say, 6 feet per second. The motion (Continued on page 267.)

\section{R A P I D T R A N S T B Y B E L T C O N V E Y O R}

\section{A PROPOSED AMPLIFICATION OF NEW YORK'S SUBWAY}

The method of rapid transit by means of continuously moving endless platforms has never as yet ro ceived the attention which its unquestionable advantages deserve; for, within certain limits of speed, it possesses a capacity for carrying passengers which is so far beyond that of any existing system as to place it in a class by itself. That the system has not been put into practical application in the solution of those problems of congested city traffic for which it is so admirably adapted, can only be explained by the extreme novelty of the method employed, the inertia of that deep-rooted conservatism, which, even in this strictly utilitarian age, exerts such a powerful controlling influence on human affairs. The construction and operation of the moving passenger platform is so simple, and its great carrying capacity is so obvious, that its advantages are readily perceived even by the layman who may perceived even by the layman who may have no particular mechanical aptitude or training; and it is certainly significant that the proposal to equip a sec-
tion of the proposed New York Subwa with a moving platform has received the indorsement of such men as Henry B. Seaman, the Chief Engineer of the Public Service Commission, and of $\mathrm{Mr}$. L. B. Stillwell, the electrical enginee who was responsible for the electrica equipment of the, Elevated Railroads and the New York Subway system. In'terest in the proposed moving plat form recommendation of the Board of Est1-
mate of this city that a moving platmate of this city that a moving plating across Manhattan Island from th East to the Hudson River below Thirty-fourth Street; and on the front page of the present issue is a secpage of the present issue is a secgeneral character of the construction both of the subway and of the moving platform itself.

In those branches of our industries, for the economical operation of which it is absolutely necessary that material be conveyed from place to place at a maximum speed and with a minimum cost, it has been found that there is no system of transportation which so perfectly fulfills these conditions as the belt conveyor. Particularly is this true where a great bulk of material, consisting of more or less finely divided units, such as coal, iron ore, and wheat, have to be moved in great quantities with as little inter- ruption as possible and without an $\bar{y}$ manipulation by hand. In this system, an endless belt moves continuously in a given direction; and facilities are provided for loading the material on the belt at any desired point and for unloading it therefrom at any desired point of delivery.

The moving platform is nothing more nor less than a huge belt conveyor, in which the material to be conveyed consists of the teeming millions which constitute the passenger traffic of a great city, with provision for loading the passengers at any point throughout the length of the platform and unloading them while the latter is in motion. The train consists of short jointed platforms, coupled together and forming an endless chain which is kept in continuous motion. This platform is

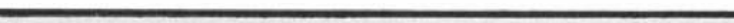

lator or moving stairway, of which many are now in operation throughout the country, removes any doubt of passengers being able after a little practice to accommodate themselves to the speed of three miles an hour involved in boarding the train.

The advantages of the arrangement as summed up by the Chief Engineer of the Public Service Commission are as follows:

1. A vastly increased capacity, and seats for all passengers.

2. There is no delay incurred by waiting for trains at stations, as the train is always there and constantly moving.

3. Passengers may board or leave the train at any point at will, and instead of placing stations one-third of a mile apart, as on the present Subway, they may be placed at every cross street, or in deed at any intermediate point, and the construction may take the form of a continuous arcade.

In its general construction the tunnel would be similar to those built for the ordinary Subway traffic. It is proposed, however, to build arcades throughout its length, with store windows at basement level, and continuous promenades between them and the barrier separating them from the Subway platforms. At each street crossing, and if it be desired, at one or more points between them, ticket booths and turnstiles will be installed -an arrangement which would permit passengers to board the cars practically at any desired point throughout the length of the subway.

The arrangements for driving the platform by electrical power are as follows: Extending longitudinally be neath each platform is a pair of $I$ RAPID TRANSIT BY BELT CONVEYOR.

seats, and it travels at a continuous uniform speed of twelve miles per hour. For transferring the passenger from the flxed station platforms to the seated platforms, there are introduced between them three narrow "loading platforms" which move at differential speeds. The flrst of these adjoining the station platform moves at three miles per hour, the next at six, and the next at nine miles per hour. The passenger who wishes to board the train, faces the direction in which it is moving, steps onto the three-mileper-hour platform, and, crossing the other two successively, takes his seat. The success of the escaneath each platform is a pair of 1 bottom of the platform, while the lower flanges serve to support the weight of the platform upon pairs of wheels, which are carried upon transverse shafts mounted at intervals of 2 feet 9 inches, upon concrete piers, as shown in the engraving. Between each pair of longitudinal I-beams is carried a pair of horizontal guide wheels which engage a guide rail that serves to keep the platform in proper alignment. At every 75 feet, 10-horse-power motors are mounted on the floor of the subway, and are connected by a chain drive (Concluded on page 268.) 


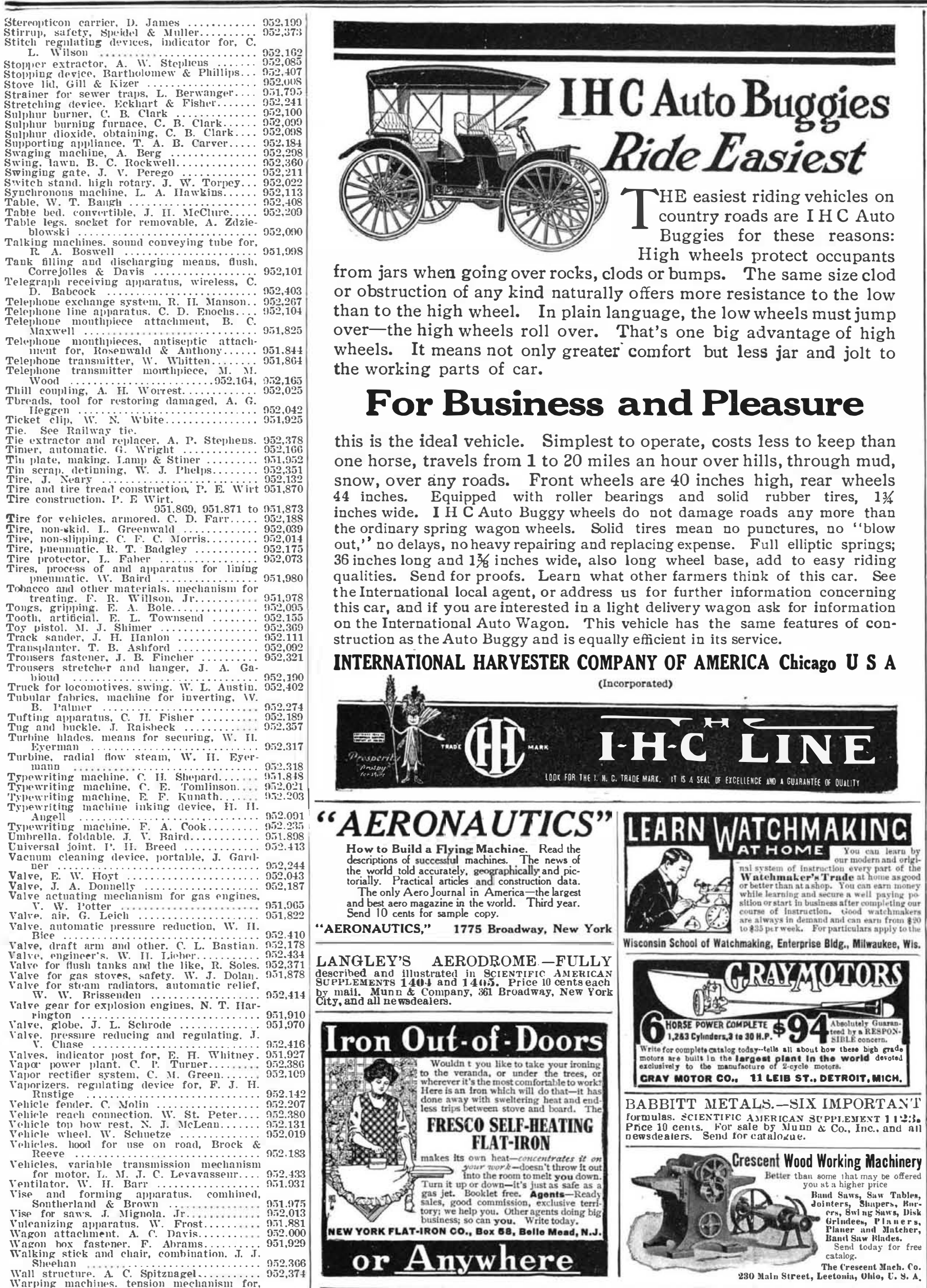
ast, aided more than was entirely de sired by the falling dews, and the conraction of the gas after the sun's rays ad so much diminished. However, by a up at a safe distance, proceeding in a curve to the northwest, until, observinghat a crowd was gathering from all points of the compass in the neighborhood of Medford, evidently calculating on our descent, and shouting loud invitations, we gratified them and promised their assistance. A large number of willing men caught hold of our long trailin rope by Mr. Lowe's direction. Our gas was allowed to escape freely, and we landed on a large sand bar, one of the best places that could have been selected, at a quarter past eight, after about sixty miles of the pleasantest voyage it is possible for man the unwinged bird, to take."

VERTICAL PHOTOGRAPHY.

ground is placed under the glass supporting the article to be photographed. The distance between the support and the background varies from three inches to eighteen inches. The greater the distance the less reflection. The color of the background is generally determined by the color of the object to be photographed. When working under the sub ject, the light can be reflected under rendering the background more tense, or on the subject proper, giving not only more illumination, but illumination of greater uniformity. Some subjects re uire a neutral ground. In this case the photographer will change his background many times during exposure. He may start out, for instance, with a pure white ground on top and remove grounds which are piled one on top of another ntil he passes through many shades, nding the exposure with probably vivid red. This changing of backgrounds during an exposure will often bring out n object that would have otherwise been Cameras are manufactured especially or work of this nature and have scales of measurements so arranged that the round glass support is part of the camera proper, but movable either way with a thumb screw, so that an allowance can be made for objects of various thicknesses. By attaching the support thicknesses. By attaching the support or revolved during the exposure, givin uniform illumination to the subject The camera may be supported by a triod in a vertical position, as shown in the illustration. When in the field the in A stand, such as shown in the illustration, may be easily made and will answer all purposes admirably. Any camera can be thus used with good reNOW READY! THE FOURTH DIMENSION SIMPLY EXPLAINED INTRODUCTION BY HENRY P. MANNINC

Price, $\$ 1.50$ net. 260 pages illustrated FRIEND of the Scientific American's donated a prize of $\$ 500.00$ for the best simply-worded A Con- C. D. Fitch, U. S. A. This essay, together with three others which were accorded honorable mention, was published in the columns of the Scientific American. As a result, so much interest was aroused in the subject of the Fourth Dimension that it seemed advisable to collect, in permane
parts of the world.

The present work pre nts twenty points of view, all of them interesting and no two quite alike. Each essay is 2500 words in length. The reading of one essay does not involve the reading of the entire work, yet the entire book gives a comprehensive view of what the layman wishes to
know about the Fourth Dimension. No abstract mathematics will be found in the volume. The essayists endeavor the explain to Fourth Dimension both by imagining the effect of transporting an ordinary third-dimensional human being into fourth-dimensional space and also by explaining a third-dimensional man's possibilities in one and two dimensional space.

Professor Manning, the leading American authority on the subject of the Fourth Dimension, nathematical prominence, and swiftly reviews the work that has been done in the field. He has also edited the essays and supplied explanatory footnotes where required. ORDER FROM YOUR BOOKDEALER OR FROM MUNN \& COMPANY, Inc., 361 Broadway, NEW YORK

A tilting tripod head, which is simple A tilting tripod head, which is simple may be used in this style of photography to a good advantage. In many cases most pleasing results have been secured for a background, a tilting top for the tripod, and the outfit is complete.

INTERNAL COMBUSTION PUMP.

(Conclucled from page 25u)

of the column of water cannot be suddenly arrested, hence the pressure in $C$ tends to fall below that of the atmosphere, and the exhaust valve $E$ opens as in through the water valves, mostly to follow the moving column in pipe $D$, but partly to rise in chamber $C$, in an effort to reach the same level within that chamber as in the suction tank. When the kinetic energy of the moving column gas has expended itself by forcing water into the high-level tank, it comes to rest, 
turn flow, the column starts to move back toward the pump, and gains veloc ity in this movement until the water reaches the level of the exhaust valve, which it shuts by impact. The result is that a certain quantity of burnt products of combustion becomes imprisoned in the cushion space $F$, and the energy of the moving column is expended in compressing this gas cushion to a greater pressure than that due to the static head of the water in the elevated tank $E T$. Consequently, a second outward movement of the column of water takes place and when the water reaches the level of valve $E$, the pressure in the space $F$ is once more atmospheric, and further movement of the water opens valve $A$ by suction against a light spring, and draws in a fresh gaseous charge. If there were no friction, the water would fall to the same level as that from which the last upward motion started; but the amount of combustible charge drawn in is slightly less than this movement would represent. Once again the column of water returns under the elevated tank pressure and compresses the charge in the combustion chamber, which is then ignited at the moment of maximum com pression, and the same cycle of operations is repeated.

The ignition is timed by a small apparatus somewhat resembling an ordinary engine indicator, which closes the electric ignition circuit at the point of maximum compression, an ordinary small battery, trembler coil, and sparking plus as are used in automobile practice.

In starting the pump for the first time compressed air is allowed to flow into the combustion chamber until the volume of air introduced is rather larger than the usual charge. The exhaust valve is then suddenly opened by means of a hand lever, and the escape of the compressed air permits a movement of the water column, which gives the cushion and suction strokes, and so draws in a fresh com bustible charge, which, when the curren is switched on and consequently fired starts the pump working regularly. When the pump is stopped in the usual way in regular work, it always stops with a fresh charge of explosive mixture present in th combustion chamber, so that it is only necessary to switch on the current and the pump is started up. This enables the pump to be set in motion from the switchboard and without any preliminaries whatever.

The pump has been severely tested, and is now in regular daily work at a large pumping installation in the Midlands, giving complete satisfaction. The absence of all complicated gearing such as exists in the ordinary explosion motor is an outstanding feature, and guards the engine against breakdown, the only part that could fail being possibly a defective mushroom valve or spring. Wear and tear is also reduced to an insignificant quantity, and the troubles incidental to lubrication are overcome.

In its simplest form the apparatus converts gas power into hydraulic power, and may, therefore, be called a gas pump; but if the power is to be taken off a rotating shaft, the high-pressure water is passed through a water turbine, and so back to the apparatus to be continually circulated. The invention can also be applied with equal facility and efficiency for the com pression of air.

The pump has been elaborately de scribed by the inventor in a paper published in the Scientific American SupPLEMENT.

\section{RAPID TRANSIT BY BELT CONVEYOR.}

(Continued from page 25\%.)

with transverse shafts which carry the driving wheels of the platform. The gradation in the rate of speed of the sections of the platform is secured by varying the diameter of these driving wheels, which are 8 inches in diameter for the 3-mile, 16 inches in diameter for the 6-mile, and 24 inches in diameter for the 9-mile platform. The driving wheels are covered with

\section{Here is the Machine}

which writes,

which adds,

which subtracts,

and

which covers the

whole field of

writing, adding

and combined

writing and adding

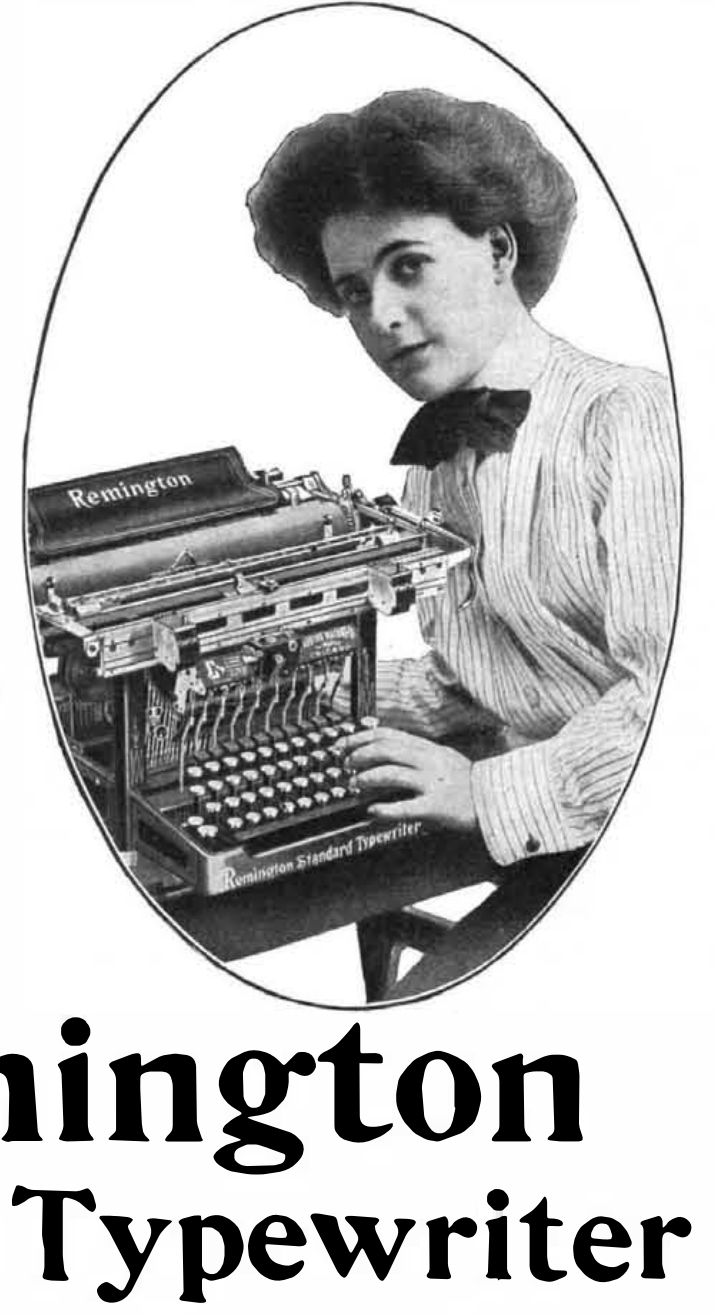

with Wahl Adding and Subtracting Attachment

Remington Typewriter Company

New York and Everywhere

\section{HALLEY AND HIS COMET}

The year 1910 is destined to be one of the most famous in astronomical history, simply because ley's comet has returned after a lapse of seventy-five years. Why not learn all about this

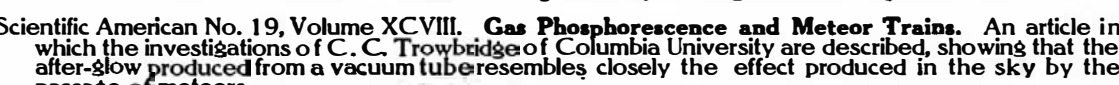

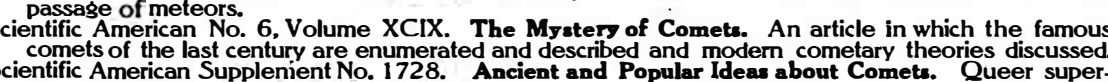

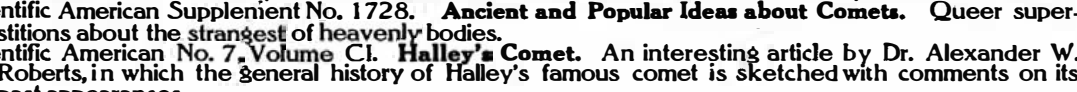

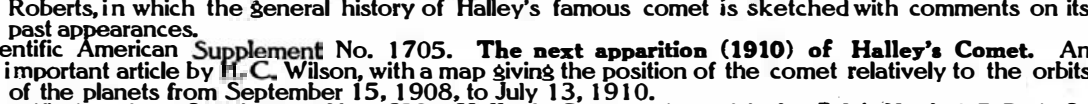

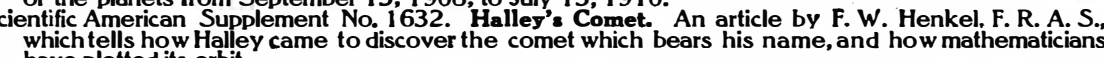
cientific American Supplement No. 1770. Edmund Halley. A biosraphy by J.E. E. Gore, M. R. I. A. of

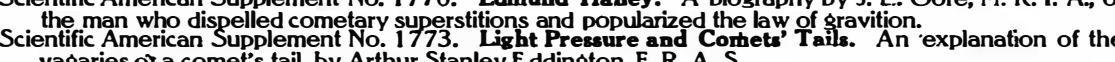

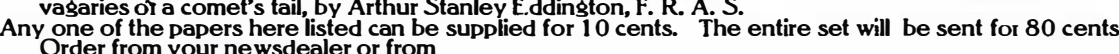
MUNN \& CO., Inc., 361 Broadway, New York City

\section{\begin{tabular}{c|c} 
JUET PUBLISRED \\
VEHICLES OF THE AIR
\end{tabular} Cas, Gasoline and

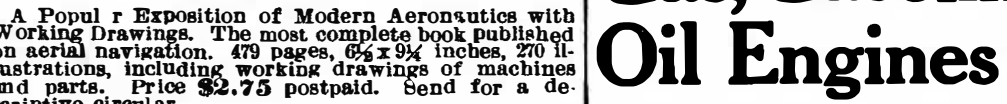
MUN \& compANY, Inc., 361 Broadnay, Nen York citr Including Producer Gas Plants W08 DURYEA BUGGYAUT

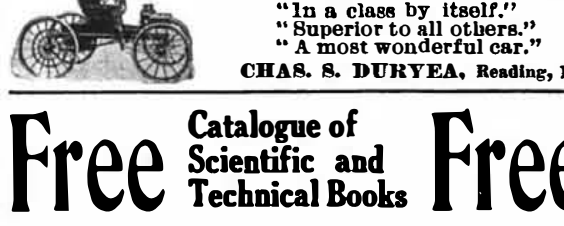

We have lust issued a new edition of our Catalogue of Scientific and Technical Books, which contains 144 pages, and a copy will be mailed free to any address on application.

MUNN \& CO., Inc., Pablishers of Sciantific Americ 361 Broadway. Now Yort

\section{By GARDNER D. HISCOX, M.E.}

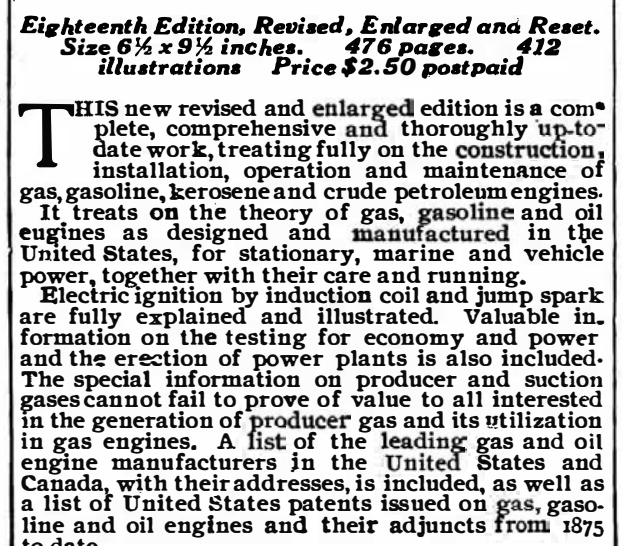

MUNN \& CO, lnce, Publisher:

362 Broedwas, Now Yort rubber, as are the horizontal central guide wheels, and consequently the motion of the platform will be both smooth and silent. The successive sections are coupled together by means of links 46 inches in length, and the coupling pins are placed at the center, from which the curves of the abutting ends of the platform sections are struck; consequently, the opening between the joints may be reduced to a minimum, and a smooth surface presented for walking, with no open spaces to bewilder or trip the passenger.

The passenger-carrying capacity of the moving platform is just double the maximum capacity of the present Subway trains. According to the figures of the Public Service Commission, the total rush-hour capacity of the five-car local trains per hour is 22,500 and of the eight-car express trains 36,000, whereas the moving platform, according to their estimate, would carry 73,500 passengers per hour. They state furthermore that for all distances less than four miles the moving platform is a quicker and more convenient mode of conveyance than the present local train service and even quicker than the local and express service combined, since a passenger may reach Times Square Station, from any local station south of Fourteenth Street (that is, supposing a moving platform were installed on a north and south avenue) quicker by the moving platform than by the local and express trains of the present Subway.

In conclusion, however, we would sound a note of warning with regard to the possible interference of any moving platform subway that may be built with any future extensions of the present Subway. In selecting the route, care should be taken to choose a location where the moving platform subway will not block any of the future through lines which must ultimately be built on practically every avenue in New York pract

\section{Why Are We Right-Handed?}

(Concluded from page 261.) the lesion on the right side. The hand and arm centers in the brain are intimately linked in the cortex with the speech centers. And certainly Crichton Browne is correct in the inference that the preferential use of the right hand and arms in voluntary movements is due to the leading part taken by the left brain. "We could not get rid of our right-handedness, try how we might; it is woven in the brain." And this, I believe, is the conclusion to which we must scientifically arrive. "In the curious disease aphasia, in which one forgets words, the lesion lies in Broca's convolution; one cannot say cup, for example, though one sees a cup; but when the right hand touches the cup, the patient at once utters its name.

Here one reflects: In the process of evolution, did the heart tend to be on the left side, and the left brain tend to greater development, because the right hand came to be the most used? Or did the right hand come to be most used, because of these heart and left-brain phenomena? I am, for my part, of the former opinion; the heart on the left side and the greater left-brain development, are effect rather than cause, coming gradually to pass as man, in the strug gle for the survival of the fittest, found right-handedness more and more advantageous.

Of course, there are professions and trades in which a certain amount of ambidexterity is essential. For example, the pianist, in playing the fugues of Bach, must produce with the left hand almost the same tones as does the right, and has to work a little harder too, for the bass notes of the piano are more thickly wired than the treble. A certain amount of ambidexterity is essential in the surgeon. Yet this gift has its disadvantages, withal; as when a colleague -skilled in this way admitted to me that before doing a thing he wasted appre- 